\title{
AWARD ACCOUNTS SPSJ Wiley Award Accounts Synthesis of Polymers Containing Group 15 Elements via Bismetallation of Acetylenic Compounds
}

\author{
By Kensuke NAKA*
}

Carbon-element bond formation is a key point of synthetic methodology for incorporating a wide variety of metallic or metalloid elements in polymer main chains. Radical 'bismetallation' to carbon-carbon triple bonds based on homolytic cleavage of element-element single bonds is one of the most useful and highly atom-economical methods for carbon-element bond formation. Syntheses of novel polymers containing group 15 elements have been achieved by ring-collapsed radical alternating copolymerization (RCRAC) of homocyclic compounds with rings built exclusively of group 15 elements with acetylenic compounds. Poly(vinylene-arsine)s were successfully prepared by a radical reaction between pentamethylpentacycloarsine (cyclo-(MeAs) $)$ or hexaphenylhexacycloarsine (cyclo-(PhAs)6 and mono-substituted acetylenic compounds using 2,2'-azobisisobutyronitrile (AIBN) as a radical initiator or irradiation with xenon lamp at room temperature. Without any radical initiator at $25^{\circ} \mathrm{C}$, cyclo-(MeAs) $)_{5}$ caused cleavage of the arsenic-arsenic bond spontaneously and copolymerized with phenylacetylene to give poly(vinylene-arsine)s. The copolymers obtained showed fluorescence properties which were influenced by the substituents of the acetylenic compounds. Poly(vinylene-phosphine)s and poly(vinylene-stibine)s were also prepared by RCRAC of cyclo-(MeP) $)_{5}$ and $c y c l o-(\mathrm{PhSb})_{6}$ with alkynes, respectively. Different reactivity of pnictogen radicals made it possible to construct the periodic vinylene-arsine-vinylene-stibine backbone. The radical terpolymerization of $c y c l o-$ $(\mathrm{MeAs})_{5}$, phenylacetylene, and a vinyl monomer and radical copolymerization of cyclic diarsine with vinyl monomers were also described.

KEY WORDS: Bismetallation / Group 15 Element / Organoarsenic Polymers / Inorganic Polymers / Cyclooligoarsines /

Synthesis of polymers having inorganic elements in polymer backbones is of interest because they can offer interesting and useful properties such as electronic, photonic, biomedical, and flame-retardant properties. ${ }^{1}$ Among them, the incorporation of a main group element such as $\mathrm{O}, \mathrm{S}, \mathrm{Se}, \mathrm{NR}$, and $\mathrm{SiR}_{2}$ into an unsaturated polymer main chain appears to be a promising way to produce materials with useful properties. ${ }^{2}$ For example, heteroatom-including poly(phenylene)s such as poly(phenylene-oxide), poly(phenylene-sulfide), and polyaniline have been industrially important as engineering plastics or electric materials. Heteroaromatic polymers, such as polythiophene and polypyrrole, are also intensively investigated and have found wide applications. Organoboron $\pi$-conjugated polymers highly extended through the empty p-orbital of the boron atom emerged as a new class of $\pi$-conjugated materials. ${ }^{3}$ To develop new polymerization methods for heteroatom-containing unsaturated polymers is of considerable interest because such polymers show unusual properties.

The introduction of inorganic elements with coordination ability into polymer main chains results in polymer ligands which can keep transition metals along their backbones. Phosphorus, arsenic, antimony and bismuth belong to group 15 elements, which have a lone pair on their atoms. The name 'pnictogen' is used for elements of this group except for nitrogen. Electronegativity of pnictogen decreases and metallic character increases down the series phosphorus to bismuth. Pnictogens often exist in the oxidation state of $+\mathrm{III}$ or $+\mathrm{V}$ as expected from their outer electronic structure of $s^{2} p^{3}$. The structures of neutral pnictogen compounds in their +III oxidation states are pyramidal, and fourth tetrahedral position is occupied with lone pairs of electrons. The bond angles are smaller than the ideal angle of tetrahedral, $109.5^{\circ}$. In the case of heavier elements, antimony and bismuth, the angles are close to $90^{\circ}$, which suggests the substitution via $\mathrm{p}$ orbitals with little s characters and the increased s character of the lone pair rather than using $\mathrm{sp}^{3}$ hybridized orbitals. Pnictogens in $+\mathrm{V}$ oxidation state exhibit Lewis acidities. The +III oxidation states of pnictogens normally act as Lewis bases or donors due to the presence of the lone pairs. Alkyl derivatives are stronger donors than aryl derivatives. Arsenic and bismuth exhibit lower basicities than phosphorus and antimony. Therefore, arsenic compounds and bismuth compounds have poorer coordination abilities than phosphorus and stibine analogues. The +III pnictogens can also exhibit Lewis acidities due to the available empty d orbitals.

One of the most famous polymers containing group 15 elements are poly(phosphazene)s (Figure 1). ${ }^{4}$ A wide variety of poly(phosphazene)s have been reported due to their characteristic flexibility, biodegradability and the ease of specific linking of side groups to the backbone. More recently, novel 

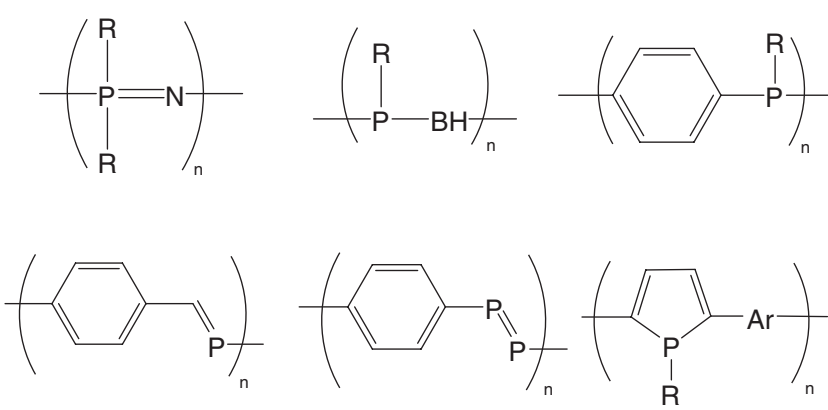

Figure 1. Recent examples of phosphorus containing polymers.

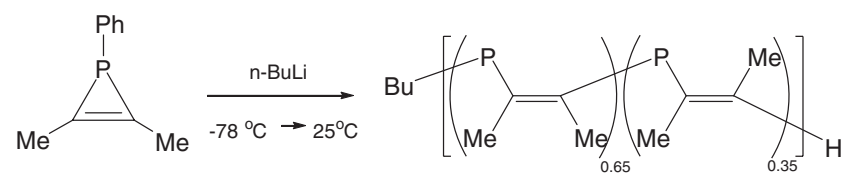

Scheme 1.

phosphorus containing polymers with attractive properties were reported (Figure 1). The ease and effective preparations of phosphinoborane polymers were achieved by a rhodium catalyst. ${ }^{5}$ The first $\pi$-conjugated $\mathrm{P}=\mathrm{C}$ containing and $\mathrm{P}=\mathrm{P}$ containing polymers were synthesized by phospha-Wittig reaction or Becker reaction. ${ }^{6,7}$ Poly ( $p$-phenylene-phosphine)s were synthesized by palladium-catalyzed condensation to show some degree of $\pi$-conjugation along the polymer chain. ${ }^{8}$ Phosphole containing polymers were also prepared. ${ }^{9}$ The anionic ring opening polymerization of phosphirene provided a poly(vinylene-phosphine) (Scheme 1). ${ }^{10}$ Despite a plenty of phosphorus containing polymers have been reported, there was no organoarsenic polymer before poly(vinylene-arsine) $\mathrm{s}^{11}$ were prepared. The detail of poly(vinylene-arsine)s is a main topic in this review. The several syntheses of polymers containing antimony elements in the main chain have been reported. ${ }^{12}$ All of these antimony polymers contain pentavalent antimony with relatively lower solubility.

\section{CARBON-MAIN GROUP ELEMENT BOND FORMA- TION VIA BISMETALLATION}

Carbon-element bond formation should be a key point of synthetic methodology for incorporating a wide variety of metallic or metalloid elements in polymer main chains. Typical synthetic methodologies for heteroatom-containing $\pi$-conjugated polymers are summarized in Figure 2. Classical methodologies usually include electrophilic or nucleophilic substitution, which have provided wide varieties of heteroatomcontaining $\pi$-conjugated polymers. Addition of metal halides to carbon-carbon unsaturated bonds, i.e., hydrometallation, is one of the most useful atom-economical methods for carbonheteroatom bond formation. ${ }^{13}$ Synthesis of $\pi$-conjugated organoboron polymers was achieved by hydroboration polymerization. ${ }^{14}$
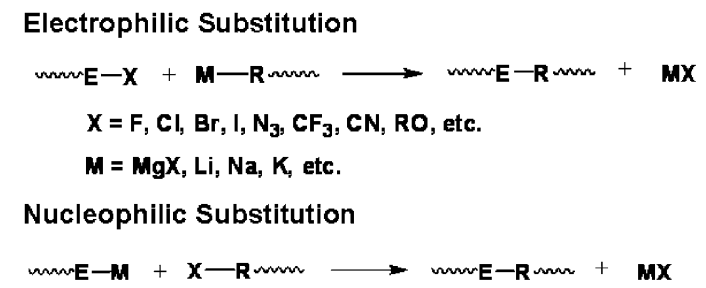

Hydrometallation

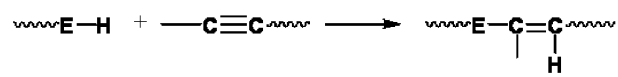

Bismetallation

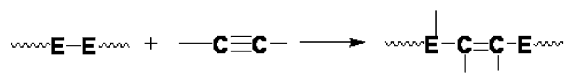

Figure 2. Typical synthetic methodologies for heteroatom-containing $\pi$ conjugated polymers.

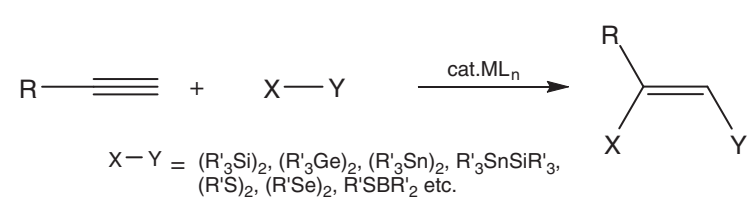

Scheme 2.

'Bismetallation' is an addition reaction accompanying the cleavage of an element-element linkage, which is one of the most attractive methodologies because two heteroatoms can be introduced into an organic compound in a single step (Figure 2). Utilizing bismetallations, a large variety of organic compounds with carbon-element bonds have been provided. ${ }^{15-18}$ Among them, bismetallations of homo- and heteroelement-element compounds to acetylenes are worthy of attention because they open a methodology for synthesis of functionalized olefins. For bismetallation to alkynes, two pathways have been demonstrated and studied well in recent researches. One is a transition metal catalyzed reaction ${ }^{15,16}$ and another is a radical reaction. ${ }^{16,17}$

For the transition metal-catalyzed reaction, group 10 metal compounds are usually used for activation of interelement linkages. Many kinds of element linkages, including group 13, 14, and 16 elements are utilized to yield bismetallated compounds. The mechanisms of the reactions have become clear in lots of studies. ${ }^{15}$ A feature of this metal-catalyzed addition reaction is its regio- and stereoselectivity. The syn addition products are obtained in the reactions (Scheme 2). Even when hetero interelement linkages are applied to this catalytic method, the regio- and stereoselective addition proceeds in some cases. ${ }^{16}$

Radical addition of heteroatom compounds to carbon-carbon triple bonds based on homolytic cleavage of heteroatomheteroatom single bonds is one of the most useful and highly atom-economical methods for carbon-heteroatom bond formation. The radical bismetallation have been less shown than the metal-catalyzed one, and mainly provides anti-form. ${ }^{17,18}$ In this case, irradiation or heating is often used for the initiation. Ogawa et al. reported photoinduced bisselenation and bistellu- 


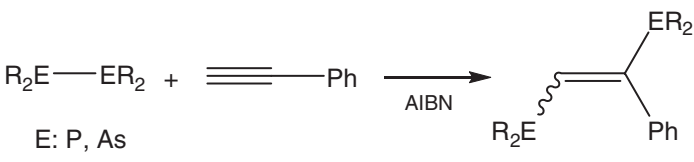

Scheme 3.

ration of alkynes with organic diselenides and ditellurides. ${ }^{18}$ Radical reactions of tetraphenyldiarsine or tetraphenyldiphosphine and phenylacetylene (initiated by AIBN or irradiation) provide the corresponding 1,2-disubstituted ethylenes (Scheme 3). ${ }^{17 \mathrm{e}}$ Recently, stereospecific diphosphination of alkynes are reported for a general rout to backbone-functionalizatied 1,2-diphosphinoethenes, which have recently attracted increasing attention in the field of nanoarchitectures. ${ }^{19}$ However, application of bismetallation to polymer syntheses is very limited.

\section{HOMOCYCLIC COMPOUNDS OF GROUP 15 ELE- MENTS}

Salvarsan, which was introduced by Ehrlich in 1910 as a remedy for syphilis, ${ }^{20}$ was studied intensively in the early part of the 20th century. The actual structure, however, is still debated. In 2005, Nicholson, et al. demonstrated that salvarsan consists of cyclic species (RAs) $)_{n}$, with $n=3$ and $n=5$ as the preferred sizes rather than the commonly written forms as shown in Figure 3. ${ }^{21}$ Though the history of the organoarsenic homocycles $^{22}$ dates back at least to the synthesis of cyclo$(\mathrm{PhAs})_{6}$ by Michaelis and Schulte in $1881,{ }^{23}$ only a few reactions of the organoarsenic homocycles with organic compounds ${ }^{24}$ has been developed compared to the extensive studies on coordination chemistry of them as ligands in transition metal complexes. ${ }^{25}$ Since radical reactions of the cyclooligoarsines are limited, revaluation the organoarsenic homocycles would open a unique chemistry.

\section{salvarsan}
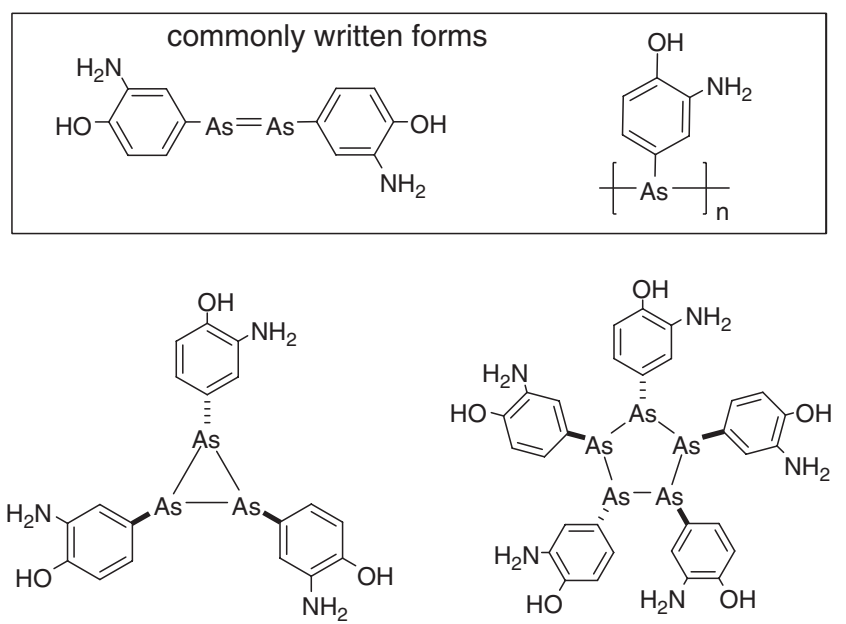

Figure 3. Structures of salvarsan.
The bond energies of element-carbon bonds and elementhydrogen bonds decrease in the sequence of $\mathrm{P}, \mathrm{As}, \mathrm{Sb}$ and $\mathrm{Bi}$. The single bond energies of element-element bonds also decrease from phosphorus to bismuth, i.e., P-P $201 \mathrm{~kJ} / \mathrm{mol}$, As-As $146 \mathrm{~kJ} / \mathrm{mol}$, Sb-Sb $121 \mathrm{~kJ} / \mathrm{mol}$, and Bi-Bi $105 \mathrm{~kJ} / \mathrm{mol}^{26}$ This sequence accounts for the number of phosphorusphosphorus or arsenic-arsenic bonded compounds are known, including $(\mathrm{RP})_{\mathrm{n}}$ and $(\mathrm{RAs})_{\mathrm{n}}$ rings, in comparison to few welldefined compounds with bismuth-bismuth bonds. The weakness of heavier element-element bond also leads to the transformation of cyclic oligomers $(\mathrm{RE})_{\mathrm{n}} \cdot{ }^{27}$ The ring-ring transformation occurs more easily in the trend of phosphorus to bismuth. Although ring equilibria of cyclooligophosphines and cyclooligoarsines proceed at elevated temperature, the transformations between cyclooligostibines or cyclooligobithmuthines occur at below room temperature. The compounds containing antimony or bismuth should be treated at lower temperature in an inert atmosphere, or need substitution by bulky groups.

The reduction of sodium methylarsonate or phenylarsonic acid with hypophosphorus acid yielded the five-membered or six-membered arsenic ring compound, resepectively. ${ }^{28,29}$ No other rings or chains of arsenic were, however, formed by this reduction, suggesting that these ring structures are stable compared to other forms containing arsenic-arsenic bonds. The five-membered cyclooligoarsine, cyclo-(MeAs) $)_{5}$, was obtained as a yellow liquid with high viscosity (Scheme 4).

After cyclo-(MeAs) $)_{5}$ was left under a nitrogen atmosphere at $25^{\circ} \mathrm{C}$ for several days, a purple black precipitate appeared, which was easily removed by a filtration under a nitrogen atmosphere. Solutions of cyclo-(MeAs) $)_{5}$ in organic solvents such as benzene, toluene, and chloroform also produced the purple-black precipitate after standing at $25^{\circ} \mathrm{C}$ for several days. The formation of the precipitate was accelerated by heating in the presence of AIBN or by the irradiation with an incandescent lamp. The resulting precipitate was insoluble in any solvent and fuming in air. According to the literature, ${ }^{30}$ the structure of the precipitate should be a linear poly(methylarsine) with a ladder structure. The arsenic-arsenic bond of the ring compound was cleaved spontaneously, and then the openchain oligoarsine stacked with each other to form the ladder structure (Scheme 5). The electronic and polymeric structures of the ladder polyarsine were theoretically investigated based on first-principles electronic structure calculations. ${ }^{31}$ The isolated polyarsine ladder chain prefers to be planar. The laddering causes the band overlap among the valence band and conduction band, and produces a metallic electronic structure by the help of the excess electrons of arsenic atoms.

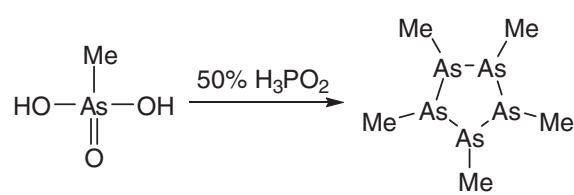

Scheme 4. 


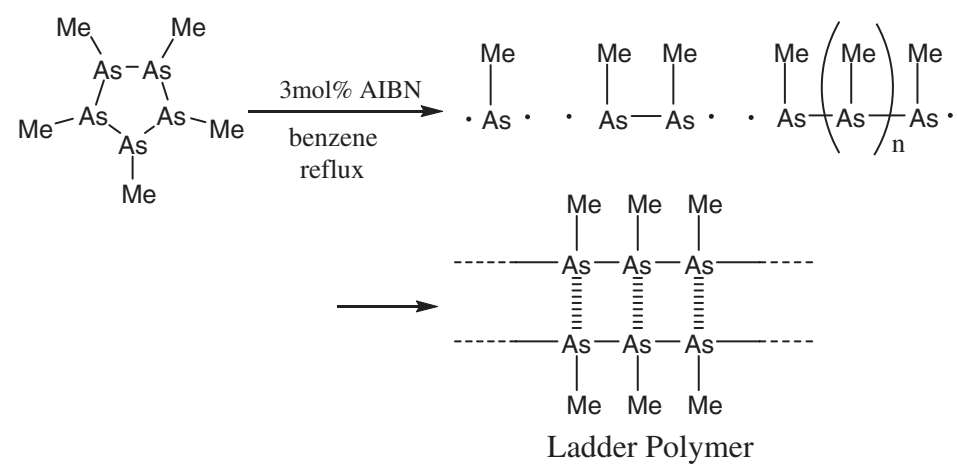

Scheme 5 .

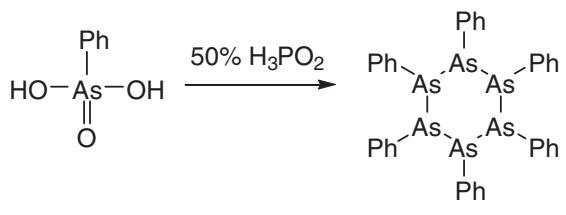

Scheme 6 .<smiles>CP(Cl)Cl</smiles><smiles>CC</smiles>

Scheme 8.<smiles>Cp1p(C)p(C)p(C)p1C</smiles>

Me<smiles>CC(c1ccccc1)(c1ccccc1)C(C)(c1ccccc1)C(C)(c1ccccc1)c1ccccc1</smiles>

Scheme 7.

The phenyl-substituted cyclooligoarsine, cyclo-(PhAs) 6 , was obtained as a pale yellow crystal after recrystallization from chlorobenzene (Scheme 6). ${ }^{32}$ The crystal showed poor solubility in organic solvents such as benzene, toluene, and chloroform. When cyclo-(PhAs) 6 was treated with $3 \mathrm{~mol} \%$ of AIBN in refluxing benzene, the heterogeneous reaction mixture became clear within $30 \mathrm{~min}$. The stable ring structure was collapsed and open-chain arsenic oligomers might be formed in the solution (Scheme 7). By cooling the clear solution to room temperature, cyclo-(PhAs) 6 was regenerated as a light yellow powder. The catalytic amount of AIBN was enough to homogenize the mixture, in other words, to collapse all of the stable six-membered ring structure, suggesting that the produced arsenic radial also contributed to the destruction of cyclo-(PhAs) $)_{6}$. In contrast to cyclo-(MeAs $)_{5}$, cyclo-(PhAs $)_{6}$ was stable at room temperature under air in the solid state, and showed no reaction even in refluxing benzene for several hours.

Cyclooligophosphines are homocyclic compounds of which backbone is constructed with only phosphorus atoms. Although interesting behaviors owing to their ability to form complexes with metal carbonyls and transition metal salts have been shown, ${ }^{33}$ there are few reports concerning reactions of cyclooligophosphines with organic compounds. ${ }^{33 a, 34}$ The methylsubstituted cyclooligophosphine was synthesized by the reduction of methyldichlorophosphine with lithium (Scheme 8). ${ }^{35}$ It is reported that the five-membered ring structure, pentamethylcyclopentaphosphine, cyclo-(MeP $)_{5}$, is mainly formed by this method and exclusively obtained by distillation under reduced pressure.

Cyclooligostibines are homocyclic compounds with rings built exclusively of antimony atoms, and have been well characterized. ${ }^{36,37}$ However, the reactivity of cyclooligostibines was reported in few papers. ${ }^{36}$ The phenyl-substituted cyclooligostibine, hexaphenylcyclohexastibine (cyclo-( $\left.\mathrm{PhSb})_{6}\right)$, was synthesized by reduction of phenylantimony dichloride using bis(cyclopentadienyl)cobalt(II) (Scheme 9). ${ }^{38}$ Non-bulky substituents $(\mathrm{R}=\mathrm{Me}, \mathrm{Et}, \mathrm{Pr}, \mathrm{Ph}$, Tol, etc.) give rise to highly flexible antimony homocycles with equilibria between rings of different size or polymers. ${ }^{39}$ Cyclic hexamers, $\mathrm{R}_{6} \mathrm{Sb}_{6}(\mathrm{R}=\mathrm{Ph}$, Tol) exist in crystalline phases. 
<smiles>C[C@@H](OCc1ccccc1)OC(C)(C)C</smiles>

Scheme 9.

\section{POLY(VINYLENE-ARSINE)S}

Poly(vinylene-arsine)s were successfully prepared by a radical reaction between the cyclic organoarsenic compounds, such as cyclo-(MeAs) 5 or cyclo-(PhAs) 6 , and mono-substituted acetylenic compounds using 2,2'-azobisisobutyronitrile (AIBN) as a radical initiator or irradiation with xenon lamp at room temperature (Scheme 10). ${ }^{11}$ Several polymerization results are summarized in Table $\mathrm{I}$. This is a novel type of radical alternating copolymerization, in which the arsenic ring compound fell into pieces and the arsenic unit was incorporated into the polymer backbone with no arsenic-arsenic bonds. Therefore, this copolymerization system is named as "ringcollapsed radical alternating copolymerization (RCRAC)". In a ${ }^{1} \mathrm{H}$ NMR spectrum of $\mathbf{2 a}$ derived from cyclo-(MeAs) $)_{5}$, an integral ratio of two peaks in a vinyl region confirmed that the trans isomer was predominantly obtained. Analysis of $\mathbf{2 a}$ by a ${ }^{13} \mathrm{C}$ NMR spectroscopy showed only one sharp resonance for the methyl carbon, suggesting that the arsenic in $\mathbf{2 a}$ existed in a trivalent state and no arsenic-arsenic bond or no oxidized arsenic was present. In the case of using cyclo-(PhAs) $)_{6}$, corresponding poly(vinylene-arsine) (3a) was obtained as a white powder. Both polymers were readily soluble in common organic solvents such as THF, chloroform and benzene.
The following reaction mechanism was proposed for RCRAC (Scheme 11). ${ }^{11,32}$ First, AIBN cleaved arsenic-arsenic bonds of the cyclooligoarsine to produce arsenic radicals. Second, the homolysis of the other arsenic-arsenic bonds proceeded spontaneously due to their instability by the destruction of the quite stable five or six-membered ring structures. In competition with this reaction, the arsenic radical added to an acetylenic compound to give a vinyl radical. Next, the vinyl radical reacted immediately with an arsenic-arsenic bond or with the arsenic radical to form a new carbon-arsenic bond. Although the carbon-arsenic bond formation seems to result in losing a growing radical and no chain growth proceeds anymore, the labile As-As bonds in the product caused homolysis easily to produce a new arsine radical, and the chain growth could restart. In this manner, repeating production of the arsine radical by the As-As bond cleavage and its addition to the acetylenic compound leads to a polymer with a simple main-chain structure, poly(vinylene-arsine). Since the vinyl radicals are more unstable and reactive than the arsenic radicals, formation of the vinyl radicals (eq 3) should be relatively slower than creation of the arsine radical (eq 2) and of the carbon-arsenic bond (eq 4). One of the propagating radicals in this copolymerization system is the vinyl radical, which might not cause recombination due to the low concentration. The vinyl radical might not react with the acetylenic compound to produce a new vinyl radical because of its instability, but reacts with the arsenic radical or the arsenicarsenic bond. The other propagating radical is the arsenic radical which cannot cause disproportionation as a termination reaction. A recombination of the arsenic radical generates the arsenic-arsenic bond which is easily cleaved under the benzene refluxing condition to reproduce the propagating arsenic radicals.

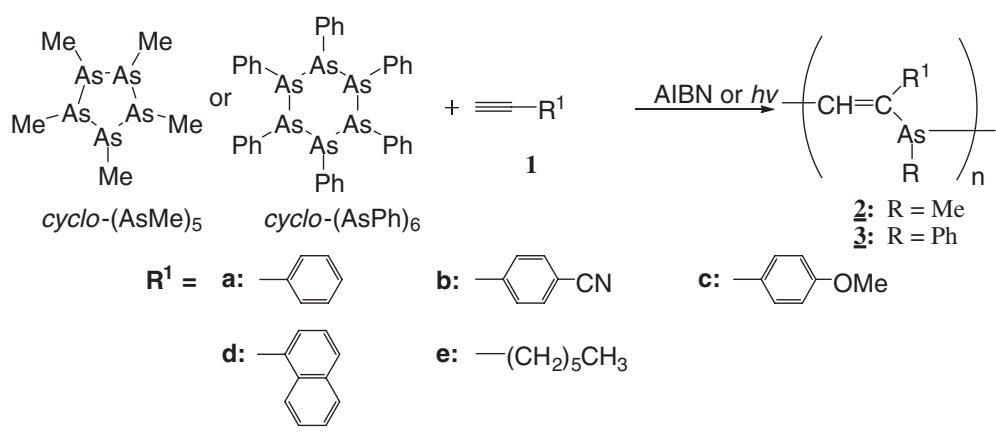

Scheme 10.

Table I. Syntheses and Optical Properties of Poly(vinylene-arsine)s

\begin{tabular}{|c|c|c|c|c|c|c|c|c|c|}
\hline Run & 2 & & polymer & $M_{\mathrm{w}}^{\mathrm{a}}$ & $M_{\mathrm{n}}{ }^{\mathrm{a}}$ & $M_{\mathrm{w}} / M_{\mathrm{n}}^{\mathrm{a}}$ & Yield $(\%)^{b}$ & Emission $\lambda_{\max }(\mathrm{nm})^{\mathrm{c}}$ & Excitation $\lambda_{\max }(\mathrm{nm})^{\mathrm{c}}$ \\
\hline 1 & $1 a$ & cyclo-(MeAs) $)_{5}$ & $2 a$ & 48700 & 11500 & 4.3 & 46 & 485 & 396 \\
\hline 2 & $1 a$ & cyclo-(PhAs $)_{6}$ & $3 a$ & 5600 & 3900 & 1.4 & 35 & 437 & 375 \\
\hline 3 & $1 b$ & cyclo-(PhAs $)_{6}$ & $3 b$ & 15100 & 8400 & 1.8 & 29 & 443,466 & 394 \\
\hline 4 & $1 c$ & cyclo-(PhAs $)_{6}$ & $3 c$ & 5100 & 3700 & 1.4 & 22 & 402 & 341 \\
\hline 5 & $1 d$ & cyclo- $(\mathrm{PhAs})_{6}$ & $3 d$ & 9900 & 7600 & 1.3 & 33 & 350 & 315 \\
\hline $6^{d}$ & 1e & cyclo-(MeAs $)_{5}$ & $2 e$ & 7800 & 6500 & 1.2 & 45 & 450 & 350 \\
\hline
\end{tabular}

${ }^{a} \mathrm{GPC}\left(\mathrm{CHCl}_{3}\right)$. Polystyrene standards. ${ }^{b}$ Isolated yields after reprecipitation into $n$-hexane. ${ }^{\mathrm{c}}$ Recorded in dilute $\mathrm{CHCl}_{3}$ solutions at room temperature. ${ }^{\mathrm{d}}$ The radical reaction was carried out with a catalytic amount of AIBN without solvent. 

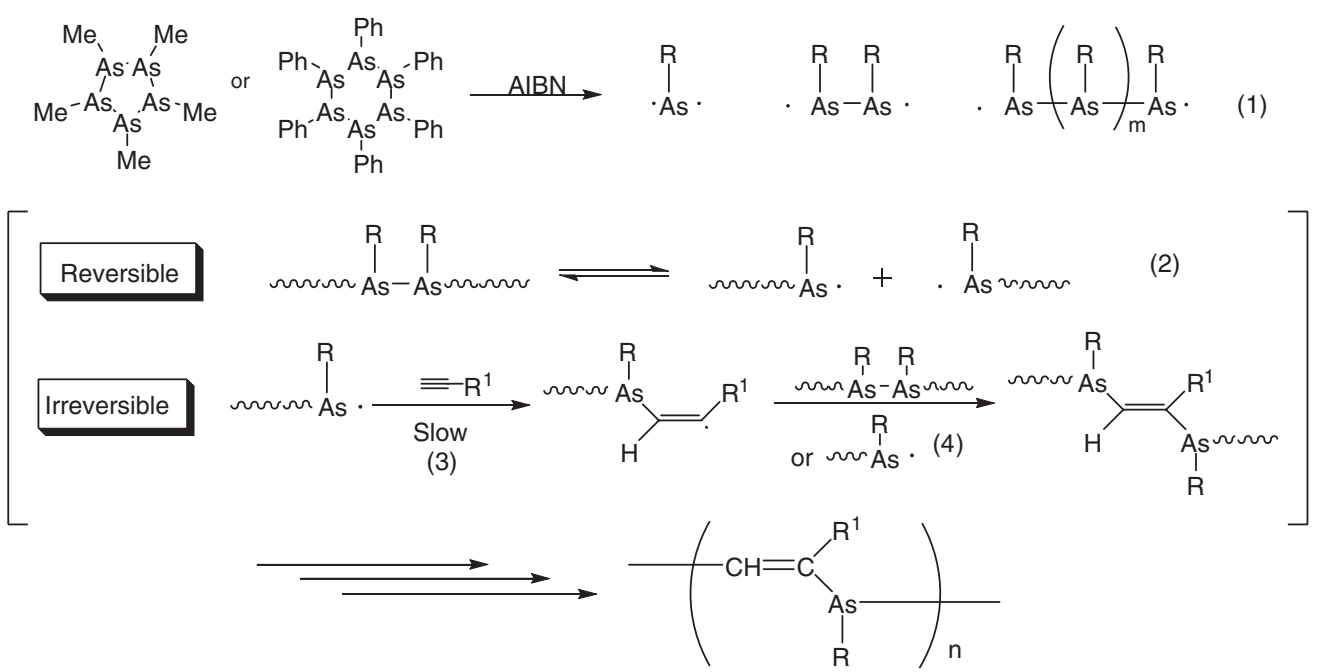

Scheme 11.

The aromatic stabilization of the vinyl radical is essential for RCRAC. The more effectively aromatic stabilization acts on the vinyl radical, the more smoothly the copolymerization progresses (Table I). ${ }^{40}$ In the case of using 4-cyanophenylacetylene (1b), the polymerization proceeded to reach nearly quantitative conversion. The copolymerization of cyclo$(\mathrm{PhAs})_{6}$ with $\mathbf{1 b}$ or naphthylacetylene (1d) was faster than that with phenylacetylene (1a) because the aromatic stabilization of the vinyl radical by 4-cyanophenyl or naphthyl group is stronger than that by phenyl group. The copolymerization of cyclo-(PhAs) 6 with 4-methoxyphenylacetylene (1c) was slightly slower than that with 1a, suggesting that electrostatic effect of the substituent might affect the reaction between the arsenic radical and the carbon-carbon triple bond. The arsenic radical may prefer to react with electron-accepting monomers rather than electron-donating monomers due to the lone pair on the arsenic atom. Both conjugative and electrostatic effect of 4cyanophenyl group made the fastest consumption of $\mathbf{1 b}$ during the copolymerization with cyclo-(PhAs) 6 among the acetylenic monomers examined.

RCRAC of cyclo-(MeAs) 5 with aliphatic acetylenes such as 1-octyne (1e) in the presence of AIBN or an incandescent lamp irradiation has been achieved to produce poly(vinylene-arsine)s with no aromatic substitution, while cyclo-(PhAs) 6 did not copolymerize with aliphatic acetylenes. ${ }^{41}$ The present results show that acetylenic comonomers with a variety of substitution are available for $R C R A C$ with cyclo-(MeAs) $)_{5}$. The progress of the copolymerization of cyclo-(MeAs) $)_{5}$ with aliphatic acetylenes was much slower than that with 1a due to the lack of the conjugative substitution to the ethynyl group.

The methyl-substituted cyclooligoarsine, cyclo-(MeAs) 5 , afforded the corresponding poly(vinylene-arsine) by the copolymerization with 1a using water as a reaction medium. The copolymerization was carried out under a nitrogen atmosphere using water, cyclo-(MeAs) $)_{5}$, 1a, sodium lauryl sulfate as an emulsifier, and potassium peroxodisulfate as a water-soluble radical initiator. The fact that the copolymerization proceeded in the presence of water excludes the possibility that ionic species contribute to the propagation of the copolymerization.

The arsenic ring compound with cyclo-(MeAs) $)_{5}$ reacted with $1 \mathrm{a}$ in chloroform at $25^{\circ} \mathrm{C}$ in the absence of any radical initiators or catalysts to produce the corresponding poly(vinylene-arsine) in moderate yield. ${ }^{32}$ The $1: 1$ alternating structure of MeAs and 1a is controlled very strictly under a wide variety of copolymerization conditions. Various solvents were found usable for affording copolymers with number-average molecular weight of more than ten thousand in moderate yields at $25^{\circ} \mathrm{C}$. The steep increase of the molecular weight of the polymer with the increase of the conversion rate of $\mathbf{1 a}$ was observed in the range of high conversion. This is a typical feature of step-reaction polymerizations such as polycondensation and polyaddition.

The methyl-substituted poly(vinylene-arsine) showed a $10 \%$ weight losses at $265^{\circ} \mathrm{C}$ (under $\mathrm{N}_{2}$ ) and $205^{\circ} \mathrm{C}$ (under air), and the phenyl-substituted one showed them at $284{ }^{\circ} \mathrm{C}$ (under $\mathrm{N}_{2}$ ) and $250^{\circ} \mathrm{C}$ (under air) (Figure 4). The poly(vinylene-arsine) with phenyl-substitution was thermally more stable than that with methyl-substitution. The glass transition temperatures $\left(T_{\mathrm{g}}\right)$

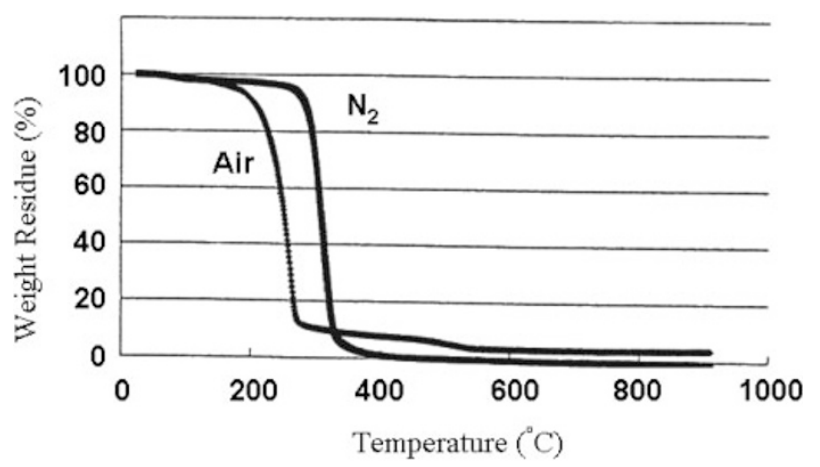

Figure 4. TGA results of the methyl-substituted poly(vinylene-arsine) (2a) under $\mathrm{N}_{2}$ and air. 


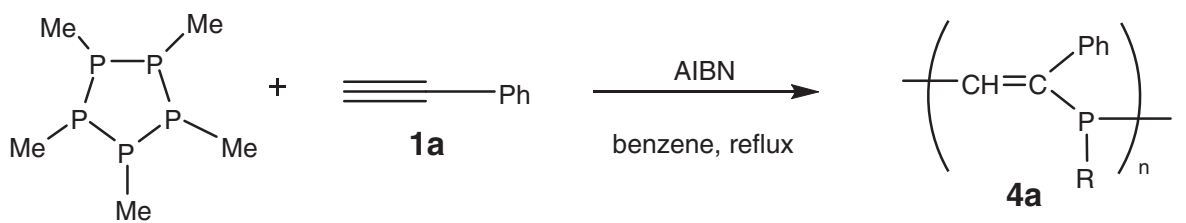

Scheme 12.

of the methyl- and phenyl-substituted polymers were 58.2 and $92.9^{\circ} \mathrm{C}$, respectively, which were determined by a DSC analysis. Both of the copolymers are stable in the solid state at room temperature. No decrease of the molecular weight or no change of the structure was observed even after exposing them to air for several months.

The electronic structures of the poly(vinylene-arsine)s were studied by UV-vis and fluorescent spectroscopies. ${ }^{40}$ In UV-vis analyses, not only strong absorption in an UV region derived from a $\pi-\pi^{*}$ transition of the benzene ring, but also small absorption in the visible region was observed, which are due to a $n-\pi^{*}$ transition in the main chain. Polymers 3a-d showed fluorescent properties. The emission was observed in the visible blue-purple region with peaks at 443 and $466 \mathrm{~nm}$. The emission peak maximum was independent of the concentration of polymer $\mathbf{3 b}$. In the excitation spectrum of $\mathbf{3 b}$ monitored at $470 \mathrm{~nm}$, the absorption was not observed in the shorter wavelength region but in the longer wavelength region with a peak at $394 \mathrm{~nm}$. This means that the absorption of $\mathbf{3 b}$ in the higher energy region and the absorption in the lower energy region are originated from the different absorbing species; $\pi-$ $\pi^{*}$ and $n-\pi^{*}$ transition. The emission of $\mathbf{3 b}$ results from only the absorption of the latter transition. Table I also summarizes emission and excitation spectral data. Each emission peak maximum of 3a-c was red-shifted in the order of $\mathbf{3} \mathbf{c}<\mathbf{3} \mathbf{a}<\mathbf{3 b}$, which coincides with the order of strength of electron-withdrawing properties of the substituents. This indicates that the donor-acceptor (arsenic atom with a lone pair and vinylene unit with electron-accepting group) repeating units made the band gap narrower and resulted in the lower energy of the emission. The optical properties of the poly(vinylene-arsine)s were tuned by changing the substituents of the acetylenic compounds. In the case of $\mathbf{3 d}$, the naphthyl group itself has a fluorescent property which is stronger than that derived from the $n-\pi^{*}$ transition in the main chain of the polymer, and therefore the emission peak due to the main chain was hidden. The absorption peaks in the excitation spectra of 3a-d showed the same order as the emission peaks because of the same reason discussed above.

The poly(vinylene-arsine)s with no aromatic substitution also showed the emission observed in the visible blue-violet region with a peak at $450 \mathrm{~nm}$ by an irradiation at $350 \mathrm{~nm}$. In the excitation spectrum of $2 \mathrm{e}$ monitored at $450 \mathrm{~nm}$, the absorption peak was observed only in the region where the wavelength was more than $310 \mathrm{~nm}$. Both of the emission and excitation peaks of 2e were blue-shifted in comparison with those of the polymer synthesized by the copolymerization of cyclo-
$(\mathrm{MeAs})_{5}$ with 1a. The substituent groups of the acetylenic compounds affected the electronic structure of the main chain of the poly(vinylene-arsine)s.

\section{POLY(VINYLENE-PHOSPHINE)S}

A conjugated polymer containing phosphorus atom in the main chain, poly(vinylene-phosphine) (4a), was synthesized by RCRAC of cyclo-(MeP) 5 and 1a (Scheme 12). ${ }^{42}$ The ${ }^{1} \mathrm{H},{ }^{13} \mathrm{C}$, and ${ }^{31} \mathrm{P}$ NMR spectroscopies of $\mathbf{4 a}$ suggested that a trans isomer of the diphosphaalkene units were mainly formed in the main chain. No RCRAC of cyclo-(MeP $)_{5}$ with 1a without AIBN proceeded even when heating up at $80^{\circ} \mathrm{C}$ or under bulk condition. These results suggest that AIBN would be required for RCRAC of cyclo-(MeP) $)_{5}$, in contrast with RCRAC of cyclo-(MeAs)5. The phosphorus-phosphorus bond is stronger than the arsenic-arsenic bond, and the phosphorus-phosphorus bond in cyclo-(MeP $)_{5}$ can not cleave spontaneously. The radical reaction of cyclo- $(\mathrm{MeP})_{5}$ with $\mathbf{1 b}$ and dimethyl acetylenedicarboxylate (1f) gave only oligomeric products. Radicals of lighter elements are expected to have less capture ability of the vinyl radicals. The capture of the vinyl radicals is hardly achieved in RCRAC of cyclo-(MeP) $)_{5}$ with electrondeficient acetylenes which provide less reactive vinyl radicals. Comparing these results with those of cyclo-(MeAs) $_{5}$, the capture ability of the vinyl radical is approved to be lower in the case of cyclo-(MeP) $)_{5}$ than that in the case of cyclo-(MeAs $)_{5}$ to provide the corresponding poly(vinylene-phosphine) despite the reaction of cyclo-(MeP $)_{5}$ with $\mathbf{1 b}$ or $\mathbf{1 c}$ proceeds.

The UV-vis absorption spectrum of $\mathbf{4 a}$ in chloroform showed a small absorption at a visible region derived from the $n-\pi^{*}$ transition in the main chain, as well as a strong absorption at a UV region derived from aromatic groups. The fluorescence spectrum of a dilute chloroform solution of $\mathbf{4 a}$ showed an emission peak at $470 \mathrm{~nm}$, which derived from the $n$ $\pi^{*}$ transition along the polymer backbone. The bathochromic shift observed in excitation spectrum of $\mathbf{4 a}$ compared with that of $\mathbf{3 a}$ might be attributed to the conformation of phosphorus or arsenic atom in the main chain. The s-character of the lone pair on a phosphorous atom is weaker than that of an aresenic atom. This might lead to increase delocalization between the lone pair electron and the $\pi$ electon of the vinylene unit.

\section{POLY(VINYLENE-STIBINE)S}

RCRAC of dimethyl acetylenedicarboxylate (1f) and cyclo$(\mathrm{PhSb})_{6}$ in the presence of a catalytic amount of AIBN in THF 


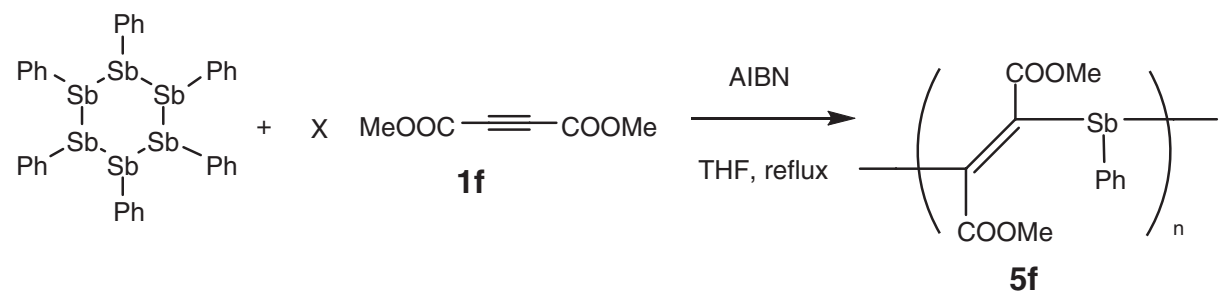

Scheme 13.

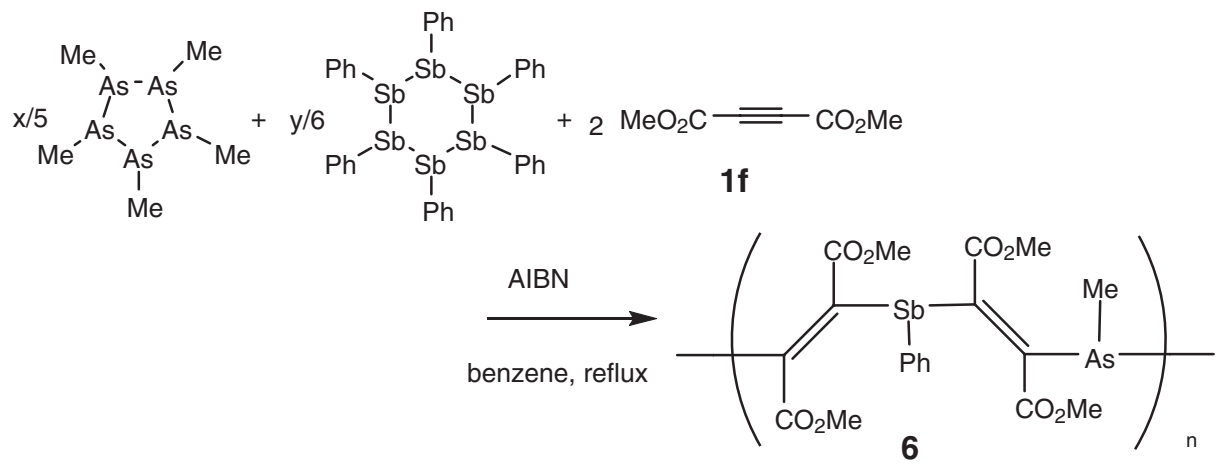

Scheme 14.

at $70{ }^{\circ} \mathrm{C}$ provided a corresponding poly(vinylene-stibine) $(\mathbf{5 f})$ of which number-average molecular weight was 4300 (Scheme 13). ${ }^{43}$ The resulting polymer is a first organic polymer which have trivalent antimony in the backbone. Polymer $\mathbf{5 f}$ was readily soluble in common organic solvents such as $\mathrm{CHCl}_{3}, \mathrm{THF}, \mathrm{DMF}$, and toluene. Polymer $\mathbf{5 f}$ was air-stable in the solid state at room temperature. No changes in the molecular weight and the structure were observed in a GPC trace and ${ }^{1} \mathrm{H}$ NMR spectrum after exposing $\mathbf{5 f}$ to air for several days.

Although RCRAC of cyclo-(PhSb) 6 and $\mathbf{1 f}$ gave Polymer 5f, no polymerization proceeded when cyclo-( $\mathrm{PhAs})_{6}$ was used in RCRAC system with 1f. Monosubstituted acetylenic monomers (1a-1c), gave low molecular weight poly(vinylenestibine)s. The difference between the case of cyclo-(PhAs) 6 and cyclo- $(\mathrm{PhSb})_{6}$ are derived from the reactivity of the corresponding radicals. The effects of conjugation or electronwithdrawing of the substituent of the acetylenic monomer promoted RCRAC. This result suggested that the arsenic radical preferred reacting with electron-accepting monomers due to the lone pair on the arsine atom. However, an excessive conjugative or electrostatic effect of the substitution of an acetylenic monomer such as $\mathbf{1 f}$ decreased the reactivity of the vinyl radicals formed from the acetylenic compounds toward the arsenic radical due to increase stability of the vinyl radicals. The arsenic radicals have more reactivity to the ethynyl groups than the antimony radicals and the antimony radicals have more reactivity toward the vinyl radicals.

The lower energy absorption edge was located at around $440 \mathrm{~nm}$. No emission was observed when $\mathbf{5 f}$ was excited at 350 or $400 \mathrm{~nm}$, while, poly(vinylene-arsine)s showed emis- sion. ${ }^{8,16,20}$ As the atomic number of pnictogen increases, the $\mathrm{s}$ character of the lone pair enhances. ${ }^{21}$ In Polymer 5f, lone pairs are much localized on antimony element because of the stronger s-character. Interaction between the lone pair electron and the $\pi$ electron of the vinylene unit might decrease compared in the case of the poly(vinylene-arsine)s..$^{8,16,20}$

\section{TERPOLYMERIZATION OF ORGANOARSENIC HOMOCYCLE}

To proceed RCRAC, the pnictogen radicals should react with both the ethynyl group and the vinyl radical. The antimony radicals are less reactive to the ethynyl groups than the arsenic radicals. The antimony radicals are more reactive towards the vinyl radicals than the arsenic radicals. There are several similar reports for the reactivity of group 16 elements. Sulfur radicals attack unsaturated bonds faster than selenic radicals ${ }^{45}$ and the selenic radicals react with carbon radicals. ${ }^{46}$ Different reactivity of the pnictogen radicals make it possible to construct a periodic vinylene-arsine-vinylene-stibine backbone. The ring-collapsed radical terpolymerization of cyclo$(\mathrm{MeAs})_{5}$, cyclo- $(\mathrm{PhSb})_{6}$ and $\mathbf{1 f}$ provided a periodic terpolymer containing both antimony atom and arsenic atom in the polymer chain (Scheme 14). ${ }^{44}$ In the case of 1:1:2 ratio of cyclo-(MeAs $)_{5}:$ cyclo- $(\mathrm{PhSb})_{6}: \mathbf{1 f}$, the obtained polymer has 1:1:2 structure of arsine, stibine and vinylene unit. Employing excess cyclo-(MeAs) $)_{5}$ did not affect the periodic structure of the terpolymerization. On the other hand, employing excess cyclo- $(\mathrm{PhSb})_{6}$ resulted in the terpolymer with more stibine units. The arsenic radical was more reactive towards $1 f$ forming the vinyl radical, while the antimony radical was more 


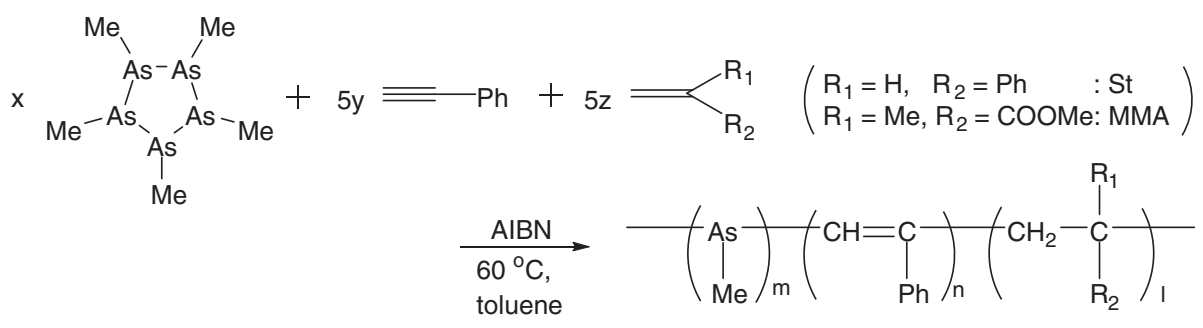

Scheme 15.

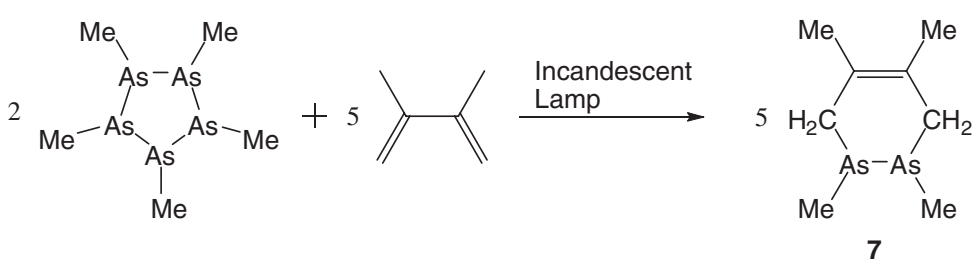

Scheme 16.
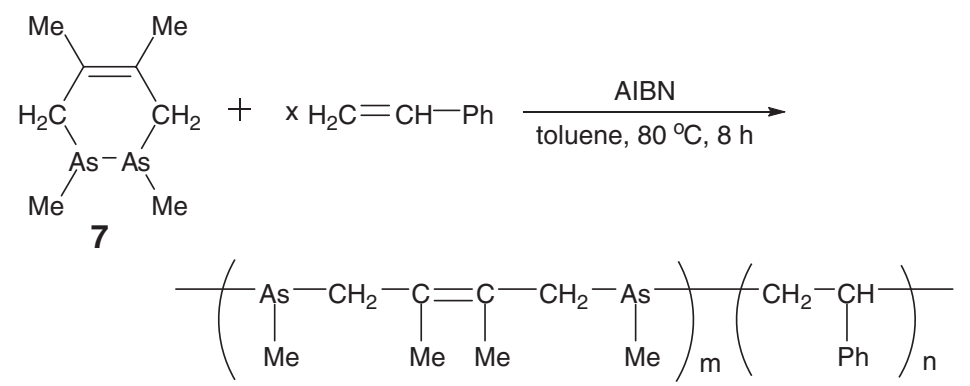

Scheme 17.

reactive towards the vinyl radical forming the terpolymer. After the arsenic radicals were consumed, the antimony radical also reacted with $\mathbf{1 f}$ thereby affecting the periodic structure of the terpolymerization. This was a first example to provide A-BA-C type polymer by a simple radical reaction to open a new area employing novel method to make polymers with periodic backbones.

The radical terpolymerization of cyclo-(MeAs) $)_{5}, \mathbf{1 a}$, and a vinyl monomer in the presence of a radical initiator gave a terpolymer which possessed two block segments of poly(vinylene-arsine) and the vinyl polymer (Scheme 15). ${ }^{47}$ In the case of employing styrene (St) or methyl methacrylate (MMA) as a vinyl monomer, terpolymers with poly(vinylene-arsine) and poly(St) or poly(MMA) segments in the backbone were obtained. The structure of the terpolymer obtained was found to have two block units, [poly(vinylene-arsine)-poly(St)]. Though the ratio of the chain-transfer reactions is unclear, this terpolymerization system is unique in the respect that it gave a terpolymer with two kinds of blocks by the simple treatment of three kinds of monomers. One of the blocks is an alternating copolymer and the other is a homopolymer. The obtained terpolymer showed fluorescent properties due to the poly(vinylene-arsine) block and the emission peak can be tuned by varying the monomer feed ratio.

\section{RADICAL COPOLYMERIZATION OF CYCLIC DIARSINE WITH VINYL MONOMERS}

Cyclic disulfides copolymerize with vinyl monomers by homolytic reactions. For example, styrene copolymerizes with 1-oxa-3,4-dithiacycloheptane (a seven-membered cyclic disulfide) $)^{48}$ or lipoamide (a five-membered cyclic disulfide with an amide group $)^{49}$ by chain transfer of propagating styryl radicals to the cyclic disulfides to give copolymers with sulfide linkages in the main chain. By ultraviolet irradiation, the disulfide linkage of trimethylene disulfide (a five-membered cyclic disulfide) is cleaved to form thiyl radicals and copolymerized with styrene. ${ }^{49}$ Therefore, cyclic compounds with elementelement bonds which cause homolysis are attractive as comonomers in radical copolymerization of vinyl monomers.

1,2,4,5-Tetramethyltetrahydrodiarsenine (7) was synthesized by photoreaction between cyclo-(MeAs) $)_{5}$ and 2,3dimethyl-1,3-butadiene being irradiated with an incandescent lamp (Scheme 16). ${ }^{50}$ Though the detailed mechanism of the reaction is unclear, 7 might be formed via radical species of arsenic and butadiene. ${ }^{50}$ Cyclic diarsine 7 is a colorless liquid with a little repugnant odor and has a good miscibility in common organic solvents such as toluene, benzene, tetra- 
hydrofuran, and chloroform. Cyclic diarsine 7, was copolymerized with St or MMA to give a polymer containing arsenic atoms in the main chain in the presence of radical initiator (Scheme 17). ${ }^{51}$ The polarity and the conjugative stabilization of the substitution of the vinyl group affected the content of the vinyl monomer unit in the copolymer. This radical copolymerization proceeded under mild conditions and is, therefore, useful for the synthesis of novel polymers with arsenic linkages in the backbone and various functional groups as pendants.

\section{CONCLUSION}

The development of new polymerization methods to heteroatom-containing unsaturated polymers is of considerable interest not only scientific interest but also preparing useful materials with unusual properties. A simplest type of the heteroatom-containing unsaturated polymers is heteroaromincluding poly(vinylene)s. However, no synthetic procedures for such polymers have been reported except poly(vinylene sulfide), which was prepared by polycondensation of sodium sulfide and trans-1,2-dichloroethylene. Synthesis of novel arsenic-containing polymers, poly(vinylene-arsine)s, have been achieved by ring-collapsed radical alternating copolymerization $(R C R A C)$ of arsenic homocycles with acetylenic compounds. Though further investigations on the mechanism are needed such as ESR analysis, the results of the studies here strongly suggest that the copolymerization proceeds via radical propagating species. Comparing the results of RCRAC of cyclo-(PhAs) $)_{6}$ and cyclo- $(\mathrm{PhSb})_{6}$, the arsenic radicals had more reactivity to the ethynyl groups and the antimony radicals had more reactivity toward the vinyl radicals.

Besides the cyclooligoarsines, a number of cyclic compounds or polymers are known of which ring or chain skeletons are made up of only one inorganic element such as silicon, germanium, phosphorus, antimony, sulfur, and so on. ${ }^{14}$ These compounds often cause homolytic cleavage by stimulation such as light or heat. The present methodology, which involves the homolytic cleavage of element-element bond of inorganic homocycles or homochains and the addition of the produced inorganic radicals to the organic monomers, would be applicable to the preparation of various inorganic polymers containing inorganic elements in the main chain. The present results demonstrate that bismetallation provides general methodology to synthesize group 15 elements-including polymers.

Received: March 31, 2008 Accepted: April 17, 2008 Published: June 11, 2008

\section{REFERENCES}

1. a) I. Manners, Angew. Chem., Int. Ed., 35, 1603 (1996). b) I. Manners, J. Polym. Sci., Part A: Polym. Chem., 40, 179 (2002). c) D. P. Gates, Annu. Rep. Prog. Chem., Sect. A: Inorg. Chem., 99, 453 (2003).

d) M. L. Turner, Annu. Rep. Prog. Chem., Sect. A: Inorg. Chem., 96, 491 (2000).
2. a) A. Sundararaman, M. Victor, R. Varughese, and F. Jäkle, J. Am. Chem. Soc., 127, 13748 (2005).

b) Z. Jin and B. L. Lucht, J. Am. Chem. Soc., 127, 5586 (2005).

c) R. C. Smith and J. D. Prorasiewicz, J. Am. Chem. Soc., 126, 2268 (2004).

d) C. W. Tsang, M. Yam, and D. P. Gates, J. Am. Chem. Soc., 125, 1480 (2003).

e) V. A. Wright and D. P. Gates, Angew. Chem., Int. Ed., 41, 2389 (2002).

3. N. Matsumi and Y. Chujo, Polym. J., 40, 77 (2008).

4. a) H. R. Allcock, Chem. Eng. News, 63, 22 (1985).

b) H. R. Allcock, J. Inorg. Organomet. Polym., 2, 197 (1992).

5. a) H. Dorn, J. M. Rodezno, B. Brunnhöfer, E. Rivard, J. A. Massey, and I. Manners, Macromolecules, 36, 291 (2003).

b) H. Dorn, R. A. Singh, J. A. Massey, J. M. Nelson, C. A. Jaska, A. J. Lough, and I. Mannars, J. Am. Chem. Soc., 122, 66698 (2000).

6. a) V. A. Wright and D. P. Gates, Angew. Chem., Int. Ed., 41, 2389 (2002).

b) R. C. Smith, X. Chen, and J. D. Protasiewicz, Inorg. Chem., 42, 5468 (2003).

c) R. C. Smith and J. D. Protasiewicz, Eur. J. Inorg. Chem., 126, 998 (2004).

d) V. A. Wright, B. O. Patrick, C. Schneider, and D. P. Gates, J. Am. Chem. Soc., 128, 8836 (2006).

7. R. C. Smith and J. D. Protasiewicz, J. Am. Chem. Soc., 126, 2268 (2004).

8. a) B. L. Lucht and N. O. St. Onge, Chem. Comm., 2097 (2000). b) Z. Jin and B. L. Lucht, J. Organomet. Chem., 653, 167 (2002).

9. a) S. S. H. Mao and T. D. Tilley, Macromolecules, 30, 5566 (1997). b) Y. Morisaki, Y. Aiki, and Y. Chujo, Macromolecules, 36, 2594 (2003).

10. L. A. Vanderark, T. J. Clark, E. Rivard, I. Manners, C. J. Slootweg, and K. Lammertsma, Chem. Comm., 3332 (2006).

11. K. Naka, T. Umeyama, and Y. Chujo, J. Am. Chem. Soc., 124, 6600 (2002).

12. a) N. Karak and S. Maiti, J. Polym. Mater., 13, 179 (1996).

b) C. E. Carraher Jr. and L. J. Hedlund, J. Macromol. Soc. Chem., A14, 713 (1980).

c) C. E. Carraher Jr., M. D. Naas, D. J. Giron, and D. R. Cerutis, J. Macromol. Sci. Chem., A19, 1101 (1983).

d) C. E. Carraher Jr. and H. S. Blaxall, Angew. Makromol. Chem., 83, 37 (1979).

e) N. Karak and S. Maiti, J. Polym. Mater., 14, 71 (1997).

f) N. A. Adrova, M. M. Koton, and L. K. Prokhorova, Vysokomol. Soedin., 9 (1964).

13. Y. Chujo, I. Tomita, Y. Hashiguchi, H. Tanigawa, E. Ihara, and T. Saegusa, Macromolecules, 24, 345 (1991).

14. N. Matsumi, K. Naka, and Y. Chujo, J. Am. Chem. Soc., 120, 5112 (1998).

15. a) A. Ogawa and N. Sonoda, J. Synth. Org. Chem. Jpn., 54, 894 (1996).

b) I. Beletskaya and C. Moberg, Chem. Rev., 99, 3435 (1999).

c) A. Ogawa, J. Organomet. Chem., 611, 463 (2000).

d) I. Beletskaya and C. Moberg, Chem. Rev., 106, 2320 (2006).

16. a) A. Naka, T. Okada, and M. Ishikawa, J. Organomet. Chem., 521, 163 (1996).

b) A. Ogawa, H. Kuniyasu, M. Takeba, T. Ikeda, N. Sonoda, and T. Hirao, J. Organomet. Chem., 564, 1 (1998).

c) L.-B. Han, J. Am. Chem. Soc., 120, 8249 (1998).

17. a) E. I. Heiba and R. M. Dessau, J. Org. Chem., 32, 3837 (1967).

b) T. G. Back and M. V. Krishna, J. Org. Chem., 53, 2533 (1988).

c) A. Ogawa, H. Yokoyama, T. Masawaki, N. Kambe, and N. Sonoda, J. Org. Chem., 56, 5721 (1991).

d) A. Ogawa, N. Takami, M. Sekiguchi, H. Yokoyama, H. Kuniyasu, I. Ryu, and N. Sonoda, Chem. Lett., 20, 2241 (1991).

e) A. Tzschach and S. Baensch, J. Prakt. Chem., 313, 254 (1971).

f) A. Ogawa, I. Ogawa, R. Obayashi, K. Umezu, M. Doi, and 
T. Hirao, J. Org. Chem., 64, 86 (1999).

18. S. Kawaguchi, S. Nagata, T. Shirai, K. Tsuchii, A. Nomoto, and A. Ogawa, Tetrahedron Lett., 47, 3919 (2006).

19. a) A. Sato, H. Yorimitsu, and K. Oshima, Angew. Chem., Int. Ed., 44, 1694 (2005).

b) D. L. Dodds, M. F. Haddow, A. G. Orpen, P. G. Pringle, and G. Woodward, Organometallics, 25, 5937 (2006).

20. P. Ehrlich, Lancet, 173, 351 (1907).

21. N. C. Lloyd, H. W. Morgan, B. K. Nicholson, and R. S. Ronimus, Angew. Chem., Int. Ed., 44, 941 (2005).

22. a) L. R. Smith and J. L. Mills, J. Organomet. Chem., 84, 1 (1975). b) L. K. Krannich and C. L. Watkins, in "Encyclopedia of Inorganic Chemistry," R. B. King, Ed., Wiley, Chichester 1, 1994, p 19.

23. A. Michaelis and C. Schulte, Chem. Ber., 14, 1912 (1881).

24. a) G. Sennyey, F. Mathey, J. Fischer, and A. Mischler, Organometallics, 2, 298 (1983).

b) G. Thiollet and F. Mathey, Tetrahedron Lett., 3157 (1979).

c) U. Schmidt, I. Boie, C. Osterroht, R. Schoer, and H.-F. Grutzmacher, Chem. Ber., 101, 1381 (1968).

25. A.-J. DiMaio and A. L. Rheingold, Chem. Rev., 90, 169 (1990).

26. P. P. Power, J. Chem. Soc., Dalton Trans., 2939 (1998).

27. "The Chemistry of Organic Arsenic, Antimony and Bismuth Compounds," S. Patai, Ed., John Wiley \& Sons, New York, 1994.

28. P. S. Elmes, S. Middleton, and B. O. West, Aust. J. Chem., 23, 1559 (1970).

29. J. W. B. Reesor and G. F. Wright, J. Org. Chem., 22, 382 (1957).

30. a) M. Y. Kraft and V. V. Katyshkina, Dokl. Akad. Nauk. SSSR, 66, 207 (1949).

b) A. L. Rheingold, J. E. Lewis, and J. M. Bellama, Inorg. Chem., 12, 2845 (1973).

31. K. Takeda and K. Shiraishi, Phys. Rev. B, 57, 6989 (1998).

32. T. Umeyama, K. Naka, and Y. Chujo, Macromolecules, 37, 5952 (2004).

33. a) M. Baudler and K. Glinka, in "The Chemistry of Inorganic Homoand Heterocycles," I. Haiduc and D. B. Sowerby, Ed., Academic Press, London, 1987, p 423.

b) M. Baudler, Angew. Chem., Int. Ed. Engl., 21, 492 (1982).

c) L. Maier, in "Organic Phosphorus Compounds," G. M. Kosolapoff and L. Maier, Ed., Wiley-Interscience, New York, 1972, p 339.
34. U. Schmidt, I. Boie, C. Osterroht, R. Schoer, and H.-F. Grutzmacher, Chem. Ber., 101, 1381 (1968).

35. M. Baudler and K. Hammerström, Z. Naturforsch., B20, 810 (1965).

36. a) M. Ates, H. J. Breunig, K. H. Ebert, S. Gülec, R. Kaller, and M. Dräger, Organometallics, 11, 145 (1992).

b) H. J. Breunig, I. Ghesner, and E. Loak, Organometallics, 20, 1360 (2001).

37. a) H. J. Breunig, K. H. Ebert, S. Gülec, and J. Probst, Chem. Ber., 128, 559 (1995).

b) H. J. Breunig and A. Soltani-Neshan, J. Organometal. Chem., 262, C27 (1984).

c) Y. Mourad, Y. Mugnier, H. J. Breunig, and M. Ateş, J. Organometal. Chem., 406, 323 (1991).

38. a) M. Nunn, D. B. Sowerby, and D. M. Wesolec, J. Organometal. Chem., 251, C45 (1983).

b) H. J. Breunig, K. H. Ebert, J. Probst, Y. Mourad, and Y. Mugnier, J. Organometal. Chem., 514, 149 (1996).

39. H. J. Breunig and R. Rösler, Chem. Soc. Rev., 29, 403 (2000).

40. T. Umeyama, K. Naka, A. Nakahashi, and Y. Chujo, Macromolecules, 37, 1271 (2004).

41. T. Umeyama, K. Naka, and Y. Chujo, J. Polym. Sci., Part A: Polym. Chem., 42, 3604 (2004).

42. K. Naka, T. Umeyama, A. Nakahashi, and Y. Chujo, Macromolecules, 40, 4854 (2007).

43. K. Naka, A. Nakahashi, and Y. Chujo, Macromolecules, 39, 8257 (2006).

44. K. Naka, A. Nakahashi, and Y. Chujo, Macromolecules, 40, 1372 (2007).

45. G. A. Russell and H. Tashtoush, J. Am. Chem. Soc., 105, 1398 (1983).

46. O. Ito, J. Am. Chem. Soc., 105, 850 (1983).

47. T. Umeyama, K. Naka, and Y. Chujo, Macromolecules, 37, 3623 (2004).

48. A. V. Tobolsky and B. Baysal, J. Am. Chem. Soc., 75, 1757 (1953).

49. T. Suzuki, Y. Nambu, and T. Endo, Macromolecules, 23, 1579 (1990).

50. U. Schmidt, I. Boie, C. Osterroht, R. Schoer, and H.-F. Grutzmacher, Chem. Ber., 101, 1381 (1968).

51. T. Umeyama, K. Naka, and Y. Chujo, J. Polym. Sci., Part A: Polym. Chem., 42, 3023 (2004).

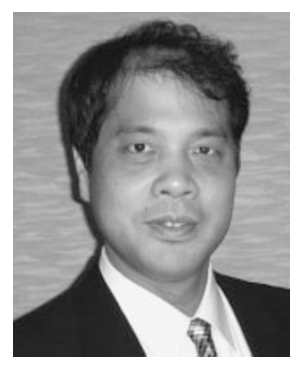

Kensuke Naka was born in Kyoto, Japan in 1962, and graduated from the Department of Synthetic Chemistry of Kyoto University, Kyoto, Japan in 1985. He studied synthetic organic chemistry and awarded Master of Engineering in 1987 at the same university. Then, he studied polymer chemistry and received his PhD from Kyoto University in 1991 under the direction of Professor Takeo Saegusa. He was appointed research assistant at the Department of Applied Chemistry of Kagoshima University in 1990. During this period, he was a postdoctoral fellow of S. L. Regen's group at Chemistry Department of Lehigh University, USA from 19911992. He was appointed research assistant at the Department of Polymer Chemistry of Kyoto University in 1996 and associate professor in 2000. In 2007, he was promoted to full professor at the Department of Chemistry and Materials Technology of Kyoto Institute of Technology. He was awarded the SPSJ (The Society of Polymer Science, Japan) Wiley award in 2007. His research interests include synthesis of organic-inorganic hybrid polymers, self-organization of $\pi$-conjugated systems via charge-transfer interaction, synthesis and selforganization of organic-inorganic nanocomposites based on metal nanoparticles., and bio-inspired controlled mineralization by polymeric templates. 